\title{
Aplikasi Bagi Waris Islam dengan Metode Forward Chaining berbasis Web
}

\author{
Desi Minarni ${ }^{1}$, Indra Griha Tofik Isa $^{2}$, Asriyanik $^{3}$ \\ ${ }_{1,2,3}$ Universitas Muhammadiyah Sukabumi \\ 1'desiminarni63@gmail.com, ${ }^{2}$ igtiku@ummi.ac.id, ${ }^{3}$ asriyanik@ummi.ac.id
}

\begin{abstract}
The current Islamic Inheritance sharing needs the third party or the expert to help in calculating the inheritance. The manual inheritance calculating, by calculating one by one can make could make the wrong result which caused by human error. The application Islamic inheritance designed as web based application using PHP and MySQL which help the people to learn Faraidh or calculate the Inheritance. In the application user could know Islamic theorem which used as Islamic Legal to decide the inheritance result. Calculating method using forward chaining, which the decision is taken when the data is collected and inputted to the system. The purpose of this research is could help the people for learning and doing inheritance calculating based on the rules of Qur'an
\end{abstract}

Keyword : Expert System, Islam Inheritance, Forward Chaining, Web Application

\begin{abstract}
Abstrak- Pembagian waris Islam yang dilakukan masyarakat saat ini masih memerlukan pihak ketiga atau seorang pakar yang membantu menghitung pembagian waris. Perhitungan waris yang dilakukan secara manual seperti menghitung data ahli waris satu persatu besar kemungkinan akan terjadinya kesalahan dalam hasil perhitungan yang terjadi akibat kelalaian manusia,. Aplikasi Bagi Waris Islam ini dirancang sebagai aplikasi berbasis web dengan bahasa pemrograman PHP, MySQL yang membantu masyarakat dalam mempelajari ilmu faraidh dan atau menghitung warisan keluarga. Dalam aplikasi ini masyarakat dapat mengetahui langsung dalil-dalil yang menjadi dasar diambilnya keputusan. Proses perhitungan dilakukan menggunakan metode forward chaining, dimana keputusan dapat diambil ketika data-data sudah terkumpul dan dimasukan kedalam aplikasi. Aplikasi ini diharapkan dapat membantu mempermudah masyarakat untuk mempelajari serta melakukan proses perhitungan bagi waris sesuai dengan aturan yang terdapat dalam Al-quran.
\end{abstract}

Kata Kunci: Sistem Pakar, Waris Islam, Forward Chaining, Web Application

\section{PENDAHULUAN}

Ilmu faraidh merupakan ilmu yang akan pertama kali hilang, adapun salah satu penyebab hilangnya yaitu ditinggalkannya ilmu faraidh karena mengartikan bahwa pembagian warisan secara adil itu diukur dengan sama rata, sehingga tidak banyak orang yang ingin mempelajari atau mengimplementasikan ilmu tersebut dan meninggalkan syariat Islam. Seperti halnya ketika Munawir Syadjali, menteri agama periode 19831992 yang menyatakan bahwa hukum bagi waris Islam tidak relevan, perbandingan 2:1 antara lakilaki dan perempuan dianggap tidak cocok, dan menggagas pembagian antara laki-laki perempuan disamaratakan yaitu 1:1. Gagasan tersebut muncul karena beliau melihat kondisi perempuan di Solo yang banyak bekerja sementara suaminya di rumah. Walaupun banyak ulama yang menentang dan gagasan tersebut tidak dimasukan ke dalam kompilasi hukum Islam (KHI), masyarakat telah terpengaruh dengan propagandanya dan banyak yang berpendapat bahwa pembagian waris yang adil itu adalah sama rata, tidak melihat perbedaan gender tapi sesuai dengan peran dalam keluarga. Sehingga pembagian waris Islam mulai ditinggalkan.

Adapun proses perhitungan warisan secara umum saat ini yaitu berkumpul keluarga dan apabila tidak ada yang mengerti akan aturan pembagian waris, keluarga mendatangkan seorang ustadz atau orang yang mengerti dan sudah terbiasa menghitung pembagian waris. Menghitung jumlah harta yang akan dibagikan dan mendata ahli waris yang ditinggalkan. Selanjutnya adalah menentukan ahli waris yang berhak mendapat warisan dan bagian masing-masing dihitung satu persatu. Dengan proses manual ini besar kemungkinan kesalahan masih dapat terjadi terutama ketika menghitung bagian dari ahli waris satu persatu yang diakibatkan oleh kelalaian manusia dan waktu 
yang digunakan untuk menghitung warisan lebih banyak.

Berdasarkan uraian permasalahan di atas, maka tujuan dari penelitian ini adalah :

1. Mempercepat dan memudahkan proses pembagian warisan menurut syariat Islam melalui aplikasi berbasis web

2. Menambah keakuratan dalam hasil perhitungan warisan setiap ahli waris.

3. Membantu masyarakat untuk mempelajari ilmu faraidh dan kembali menjalankan aturan yang terdapat dalam Al-quran.

\section{TINJAUAN PUSTAKA}

\section{A. Sistem Pakar}

Sistem pakar adalah aplikasi berbasis komputer yang digunakan untuk menyelesaikan masalah sebagaimana yang dipikirkan oleh pakar. Pakar yang dimaksud disini adalah orang mempunyai keahlian khusus yang dapat menyelesaikan masalah yang tidak dapat diselesaikan oleh orang awam [1].

\section{B. Forward Chaining}

Forward Chaining adalah metode pencarian/ penarikan kesimpulan yang berdasarkan pada data atau fakta yang ada menuju kesimpulan, penelusuran dimulai dari fakta yang ada lalu bergerak maju melalui premis-premis untuk menuju ke kesimpulan/bottom up reasoning. Forward Chaining melakukan pencarian dari suatu masalah kepada solusinya. Jika klausa premis sesuai dengan situasi, maka proses akan memberikan kesimpulan [4].

\section{Hukum Waris menurut Syariat Islam}

Hukum pembagian waris Islam dijelaskan dalam Al-quran, dimana sumber utamanya terdapat dalan Q.S An-Nisa:11-12 [2] Namun sebelum harta waris dibagikan kepada ahli waris, ada beberapa hak yang wajib didahulukan:

1. Biaya mengurus jenazah, artinya membiayai pengurusan jenazah seperti pembelian kain kafan, upah menggali kubur, dan lainnya.

2. Utang, artinya muwarits (orang yang meninggal) memiliki utang. Hendaklah utang tersebut dibayar dari harta peninggalannya sebelum dibagikan.

3. Wasiat, artinya muwarits memiliki wasiat untuk penggunakan sebagian hartanya. Wasiat dapat dilakukan jika harta yang diwasiatkan maksimal sepertiga dari harta peninggalannya. Adapaun jika lebih, ikuti saja sepertiganya.

Adapun ikatan yang berhak dan berpeluang menjadi ahli waris ada 4, yaitu:

1. Hubungan keluarga dengan muwarits (Q.S. An-Nisa:7)
2. Hubungan perkawinan dengan muwarits (Q.S. An-Nisa:12)

3. Hubungan dengan jalan memerdekakan dari perbudakan

4. Hubungan sesama muslim, muwarits yang tidak memiliki ahli waris yang tentu, maka harta waris diserahkan ke Baitul Maal untuk umat islam.

D. Ahli Waris

Dibawah ini merupakan 25 orang (15 pihak laki-laki dan 10 pihak perempuan) yang berhak atau berpeluang untuk mendapat warisan dari orang yang meninggal dunia.

1. Pihak Laki-laki

a. Anak laki-laki

b. Cucu laki-laki dari anak laki-laki

c. Bapak

d. Kakek dari bapak

e. Saudara laki-laki seibu sebapak

f. Saudara laki-laki sebapak

g. Saudara laki-laki seibu

h. Anak laki-laki dari saudara laki-laki seibu sebapak

i. Anak laki-laki dari saudara laki-laki sebapak

j. Paman dari bapak seibu sebapak

k. Paman dari bapak sebapak

1. Anak laki-laki dari paman yang seibu sebapak

m. Anak laki-laki dari paman sebapak

n. Suami

o. Laki-laki yang memerdekakan pewaris

Jika 15 orang tersebut ada semua, maka yang mendapat warisan hanya 3 orang yaitu bapak, anak laki-laki, dan suami.

2. Pihak Perempuan

a. Anak perempuan

b. Cucu perempuan dari anak laki-laki

c. Ibu

d. Nenek dari bapak

e. Nenek dari ibu

f. Saudara perempuan seibu sebapak

g. Saudara perempuan sebapak

h. Saudara perempuan seibu

i. Istri

j. Perempuan yang memerdekakan muwarits.

Jika dari 10 orang tersebut semuanya ada, maka yang mendapat warisan hanya 5 orang yaitu istri, anak perempuan, cucu perempuan dari anak lakilaki, ibu, saudara perempuan yang seibu sebapak.

Dan apabila 25 ahli waris semua ada, yang dapat menerima harta waris hanya 5 orang yaitu suami atau istri, ibu, bapak, anak laki-laki, anak 
perempuan. Anak yang masih berada dalam kandungan ibunya juga mendapat warisan.

\section{METODOLOGI PENELITIAN}

Metode penelitian yang dilakukan dengan pendekatan kualitatif, sedangkan dalam tahap pengembangan sistem menggunakan metode waterfall [3].

A. Langkah-langkah Penelitian

1. Pengumpulan Data

Kegiatan pengumpulan data yang dilakukan penulis adalah sebagai berikut:

a. Wawancara

Penulis melakukan wawancara ke Pengadilan Agama Kota Sukabumi untuk mengetahui tentang pembagian warisan menurut syariat Islam dan keterlibatan pengadilan dalam pembagian harta warisan. Wawancara dilakukan kepada Bapak H. Endang Jajuli, S.Ag (Bagian Panitera Pengadilan Agama) sebagai narasumber

b. Kuesioner

Penulis menyebar lembar kuesioner guna mengetahui tanggapan dari masyarakat untuk mengetahui tingkat kesulitan pembagian waris islam dan tingkat kebergunaan sebuah aplikasi bagi waris.

c. Studi Pustaka

Studi pustaka dilakukan untuk memperdalam ilmu tentang pembagian waris Islam, mulai dari ahli waris, kadar bagian, penghalang, hingga perhitungan untuk menghasilkan hasil akhir pembagian waris.

B. Analisis Sistem

Analisis sistem yang dilakukan penulis menghasilkan:

1. Analisis sistem yang berjalan

2. Analisis permasalahan

3. Analisis sistem yang diusulkan

C. Perancangan Sistem

Perancangan Sistem yang dilakukan dengan pemodelan Unified Modelling Language (UML) dengan pembuatan diagram sebagai berikut:
1. Usecase diagram
2. Class diagram
3. Activity diagram
4. Sequence diagram

D. Implementasi Sistem

Setelah tahap perancangan selesai, tahapan selanjutnya adalah mengimplementasikan rancangan tersebut. Penulis menggunakan:

1. PHP, HTML sebagai bahasa pemrograman
2. MySQL sebagai basis data

3. XAMPP sebagai server

E. Pengujian Sistem

Pada penelitian ini, penulis akan melakukan pengujian aplikasi menggunakan Black Box Testing, dimana aplikasi diuji dari tampilan luar (interface) dan fungsionalitas aplikasi dengan cara menguji sistem input dan outputnya dengan melibatkan salah seorang hakim di Pengadilan Agama Sukabumi.

\section{HASIL DAN PEMBAHASAN}

A. Analisis Sistem

1. Analisis Sistem Berjalan

Sistem yang berjalan dalam perhitungan bagi waris islam yang secara umum dilakukan oleh masyarakat saat ini yaitu:

a. Mendata identitas dan harta muwarits yang yang sudah dikurangi dengan hutang, biaya mengurus jenazah, dan wasiat (apabila ada).

b. Mendata keluarga yang ditinggalkan, yang akan menjadi calon ahli waris.

c. Menentukan ahli waris yang berhak mendapat warisan sesuai dengan ketentuan yang ada dalam ilmu faraidh, serta kadar bagiannya.

d. Menghitung nominal harta yang didapatkan setiap ahli waris satu persatu.

e. Mencatat hasil perhitungan yang nantinya agar disetujui oleh seluruh pihak keluarga.

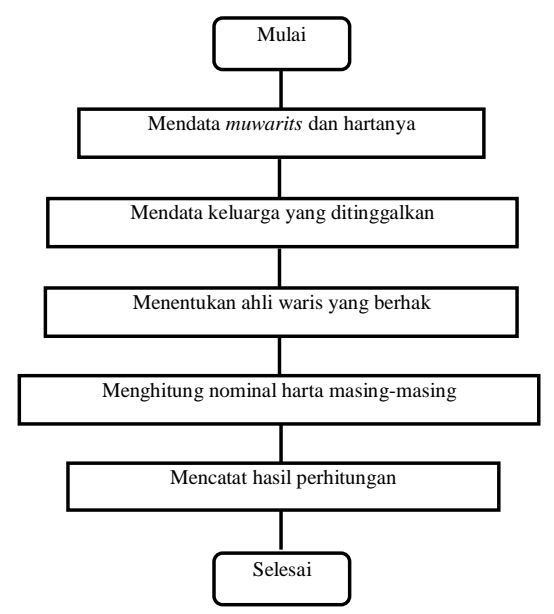

Gambar 1. Alur Kerja Sistem yang Berjalan

2. Analisis Permasalahan

Permasalahan yang muncul dari hasil analisis sistem yang berjalan yaitu:

a. Apabila di keluarga tidak ada yang paham ilmu faraidh dan sulit ditemukannya ahli ilmu faraidh. 
b. Kemungkinan menghitung dari awal ketika terjadi kesalahan di pertengahan proses hitung.

c. Menggunakan waktu lama, karena proses hitung dilakukan satu persatu dan berurutan

3. Analisis Kebutuhan dan Usulan Sistem Dari hasil analisis permasalahan di atas, penulis menganalisis kebutuhan dan sistem yang diusulkan.

Adapun hasil dari analisis kebutuhan yaitu:

a. Diperlukan suatu alat bantu, yang dapat membantu proses menghitung bagi waris Islam.

b. Diperlukan alat untuk meminimalisir atau bahkan bisa menghapus kemungkinan kesalahan yang terjadi dalam proses menghitung bagi waris, mempercepat dan menghasilkan data lebih akurat.

Dari kebutuhan di atas, penulis mengusulkan untuk membuat sebuah aplikasi. Sehingga proses menghitung warisan mengalami perubahan sebagai berikut:

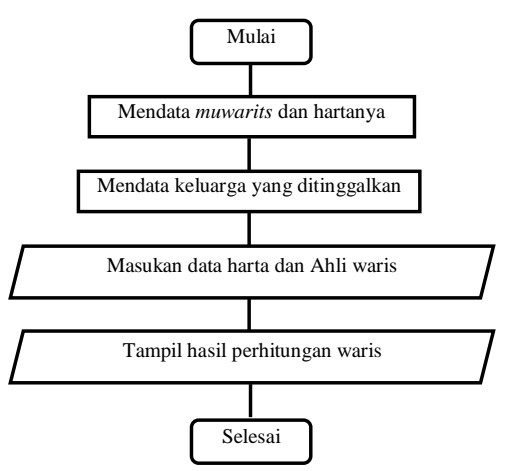

Gambar 2. Alur Kerja Sistem yang Diusulkan

B. Perancangan Sistem

Berikut ini merupakan rancangan sistem dalam membangun aplikasi bagi waris Islam:

1. Tabel Ahli Waris

Tabel 1. Tabel Ahli Waris

\begin{tabular}{|c|c|c|c|}
\hline Kode & Ahli Waris & Kode & Ahli Waris \\
\hline A001 & Suami/Istri & A011 & $\begin{array}{l}\text { Saudara } \\
\text { Kandung }\end{array}$ \\
\hline A002 & Bapak & A012 & $\begin{array}{l}\text { Saudari } \\
\text { Kandung }\end{array}$ \\
\hline A003 & Ibu & A013 & $\begin{array}{l}\text { Saudara } \\
\text { Sebapak }\end{array}$ \\
\hline A004 & Anak Laki-laki & A014 & $\begin{array}{l}\text { Saudari } \\
\text { Sebapak }\end{array}$ \\
\hline A005 & Anak Perempuan & A015 & $\begin{array}{l}\text { Saudara dan } \\
\text { saudari seibu }\end{array}$ \\
\hline A006 & Kakek dari Bapak & A016 & $\begin{array}{l}\text { Keponakan } \\
\text { laki-laki dari } \\
\text { saudara } \\
\text { kandung }\end{array}$ \\
\hline
\end{tabular}

\begin{tabular}{|c|c|c|c|}
\hline Kode & Ahli Waris & Kode & Ahli Waris \\
\hline $\mathrm{A} 007$ & Nenek dari Bapak & A017 & $\begin{array}{l}\text { Keponakan } \\
\text { Laki-laki dari } \\
\text { saudara } \\
\text { sebapak }\end{array}$ \\
\hline A008 & Nenek dari Ibu & A018 & $\begin{array}{l}\text { Paman } \\
\text { kandung }\end{array}$ \\
\hline A009 & $\begin{array}{l}\text { Cucu Laki-laki dari } \\
\text { anak Laki-laki }\end{array}$ & A019 & $\begin{array}{l}\text { Paman } \\
\text { Sebapak }\end{array}$ \\
\hline A010 & $\begin{array}{l}\text { Cucu Perempuan } \\
\text { dari anak Laki-laki }\end{array}$ & $\begin{array}{l}\text { A020 } \\
\text { A021 }\end{array}$ & $\begin{array}{l}\text { Anak Paman } \\
\text { Sekandung } \\
\text { Anak Paman } \\
\text { Sebapak }\end{array}$ \\
\hline
\end{tabular}

2. Tabel Kadar Bagian

Tabel 2. Kadar Bagian

\begin{tabular}{lll}
\hline NO & KODE & \multicolumn{1}{c}{$\begin{array}{c}\text { KADAR } \\
\text { BAGIAN }\end{array}$} \\
\hline 1 & K1 & $1 / 2$ \\
2 & K2 & $1 / 3$ \\
3 & K3 & $1 / 4$ \\
4 & K4 & $1 / 6$ \\
5 & K5 & $1 / 8$ \\
6 & K6 & $2 / 3$ \\
7 & K7 & Ashabah (sisa) \\
8 & K8 & Terhalang \\
\hline
\end{tabular}

3. Tabel Solusi

Tabel 3. Tabel Solusi

\begin{tabular}{|c|c|c|}
\hline KODE & SOLUSI & \\
\hline S01 & $\begin{array}{l}\mathrm{A} 001=\mathrm{k} 3 / \mathrm{k} 5 ; \quad \mathrm{A} 004=\mathrm{k} 7 \\
\mathrm{~A} 002=\mathrm{k} 4 ; \mathrm{A} 003=\mathrm{k} 4\end{array}$ & $\mathrm{~A} 005=\mathrm{k} 7$ \\
\hline S02 & $\begin{array}{l}\mathrm{A} 001=\mathrm{k} 3 / \mathrm{k} 5 ; \quad \mathrm{A} 004=\mathrm{k} 7 \\
\mathrm{~A} 002=\mathrm{k} 4 ; \mathrm{A} 008=\mathrm{k} 4\end{array}$ & $\mathrm{~A} 005=\mathrm{k} 7$ \\
\hline S03 & $\begin{array}{l}\mathrm{A} 001=\mathrm{k} 3 / \mathrm{k} 5 \\
\mathrm{~A} 002=\mathrm{k} 4\end{array}$ & $\mathrm{~A} 005=\mathrm{k} 7$; \\
\hline S04 & $\begin{array}{l}\mathrm{A} 001=\mathrm{k} 3 / \mathrm{k} 5 ; \quad \mathrm{A} 004=\mathrm{k} 7 \\
\mathrm{~A} 006=\mathrm{k} 4 ; \mathrm{A} 003=\mathrm{k} 4\end{array}$ & $\mathrm{~A} 005=\mathrm{k} 7$ \\
\hline S05 & $\begin{array}{l}\mathrm{A} 001=\mathrm{k} 3 / \mathrm{k} 5 ; \quad \mathrm{A} 004=\mathrm{k} 7 ; \\
\mathrm{A} 006=\mathrm{k} 4 ; \mathrm{A} 008=\mathrm{k} 4 ; \mathrm{A} 007=\mathrm{k} 4\end{array}$ & $\mathrm{~A} 005=\mathrm{k} 7$ \\
\hline S06 & $\begin{array}{l}\mathrm{A} 001=\mathrm{k} 3 / \mathrm{k} 5 ; \quad \mathrm{A} 004=\mathrm{k} 7 \\
\mathrm{~A} 006=\mathrm{k} 4 ; \mathrm{A} 008=\mathrm{k} 4\end{array}$ & $\mathrm{~A} 005=\mathrm{k} 7$ \\
\hline S07 & $\begin{array}{l}\mathrm{A} 001=/ \mathrm{k} 3 / \mathrm{k} 5 ; \quad \mathrm{A} 004=\mathrm{k} 7 ; \\
\mathrm{A} 006=\mathrm{k} 4 ; \mathrm{A} 007=\mathrm{k} 4\end{array}$ & $\mathrm{~A} 005=\mathrm{k} 7$ \\
\hline S08 & $\begin{array}{l}\mathrm{A} 001=\mathrm{k} 3 / \mathrm{k} 5 \\
\mathrm{~A} 006=\mathrm{k} 4\end{array}$ & $\mathrm{~A} 005=\mathrm{k} 7$ \\
\hline S09 & $\begin{array}{l}\mathrm{A} 001=\mathrm{k} 3 / \mathrm{k} 5 \\
\mathrm{~A} 003=\mathrm{k} 4\end{array}$ & $\mathrm{~A} 005=\mathrm{k} 7$; \\
\hline S10 & $\begin{array}{l}\mathrm{A} 001=\mathrm{k} 3 / \mathrm{k} 5 ; \quad \mathrm{A} 004=\mathrm{k} 7 \\
\mathrm{~A} 008=\mathrm{k} 4 ; \mathrm{A} 007=\mathrm{k} 4\end{array}$ & $\mathrm{~A} 005=\mathrm{k} 7$ \\
\hline S11 & $\begin{array}{l}\mathrm{A} 001=\mathrm{k} 3 / \mathrm{k} 5 \\
\mathrm{~A} 008=\mathrm{k} 4\end{array}$ & $\mathrm{~A} 005=\mathrm{k} 7$ \\
\hline S12 & $\begin{array}{l}\mathrm{A} 001=\mathrm{k} 3 / \mathrm{k} 5 \\
\mathrm{~A} 007=\mathrm{k} 4\end{array}$ & $\mathrm{~A} 005=\mathrm{k} 7$ \\
\hline S13 & $\mathrm{A} 001=\mathrm{k} 3 / \mathrm{k} 5 ; \mathrm{A} 004=\mathrm{k} 7 ; \mathrm{A} 005=\mathrm{k}$ & \\
\hline S14 & $\begin{array}{l}\mathrm{A} 001=\mathrm{k} 3 / \mathrm{k} 5 ; \quad \mathrm{A} 009=\mathrm{k} 7 ; \\
\mathrm{A} 005=\mathrm{k} 1 / \mathrm{k} 6 ; \mathrm{A} 002=\mathrm{k} 4 ; \mathrm{A} 003=\mathrm{k}\end{array}$ & $\mathrm{A} 010=\mathrm{k} 7$ \\
\hline S15 & $\begin{array}{l}\mathrm{A} 001=\mathrm{k} 3 / \mathrm{k} 5 ; \quad \mathrm{A} 009=\mathrm{k} 7 ; \\
\mathrm{A} 005=\mathrm{k} 1 / \mathrm{k} 6 ; \mathrm{A} 002=\mathrm{k} 4 ; \mathrm{A} 008=\mathrm{k}\end{array}$ & A010=k7 \\
\hline S16 & $\mathrm{A} 001=\mathrm{k} 3 / \mathrm{k} 5$ & $\mathrm{~A} 010=\mathrm{k} 7$ \\
\hline
\end{tabular}




\section{KODE}

SOLUSI

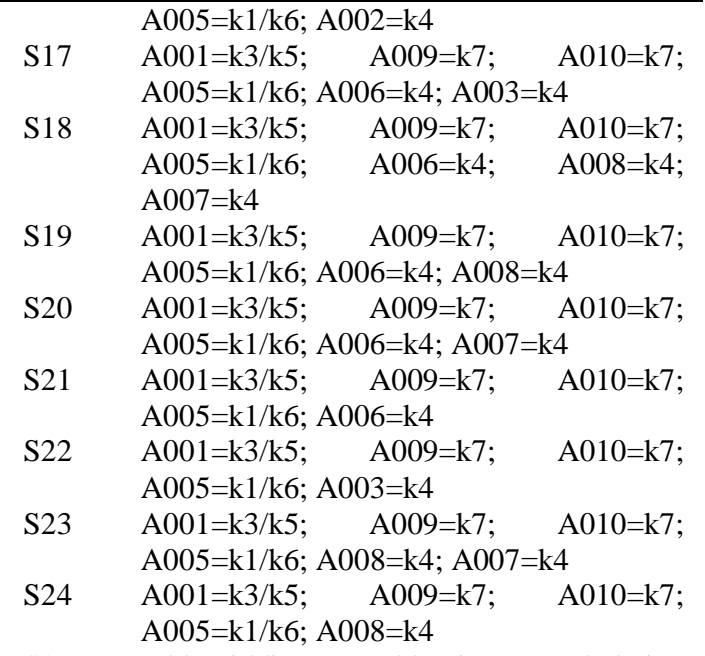

$\mathrm{S} 25 \quad \mathrm{~A} 001=\mathrm{k} 3 / \mathrm{k} 5 ; \quad \mathrm{A} 009=\mathrm{k} 7 ; \quad \mathrm{A} 010=\mathrm{k} 7$; $\mathrm{A} 005=\mathrm{k} 1 / \mathrm{k} 6 ; \mathrm{A} 007=\mathrm{k} 4$

S26 A001 $=\mathrm{k} 3 / \mathrm{k} 5 ; \quad \mathrm{A} 009=\mathrm{k} 7 ; \quad \mathrm{A} 010=\mathrm{k} 7$; $\mathrm{A} 005=\mathrm{k} 1 / \mathrm{k} 6$

S27 A001 $=\mathrm{k} 1 / \mathrm{k} 3 / \mathrm{k} 5 ; \quad \mathrm{A} 010=\mathrm{k} 1 / \mathrm{k} 4 / \mathrm{k} 6 / \mathrm{k} 8$ $\mathrm{A} 005=\mathrm{k} 1 / \mathrm{k} 6$ A002 $=\mathrm{k} 4+\mathrm{k} 7 ; \mathrm{A} 003=\mathrm{k} 4$

S28 A001 $=\mathrm{k} 1 / \mathrm{k} 3 / \mathrm{k} 5 ; \quad \mathrm{A} 010=\mathrm{k} 1 / \mathrm{k} 4 / \mathrm{k} 6 / \mathrm{k} 8$; $\mathrm{A} 005=\mathrm{k} 1 / \mathrm{k} 6$ A002=k4+k7; A008=k4

S29 A001=k1/k3/k5; A010=k1/k4/k6/k8; $\mathrm{A} 005=\mathrm{k} 1 / \mathrm{k} 6 \mathrm{~A} 002=\mathrm{k} 4+\mathrm{k} 7$

$\mathrm{S} 30 \quad \mathrm{~A} 001=\mathrm{k} 1 \mathrm{k} 3 / \mathrm{k} 5 ; \quad \mathrm{A} 010=\mathrm{k} 1 / \mathrm{k} 4 / \mathrm{k} 6 / \mathrm{k} 8 ;$ $\mathrm{A} 005=\mathrm{k} 1 / \mathrm{k} 6 ; \mathrm{A} 006=\mathrm{k} 4 ; \mathrm{A} 003=\mathrm{k} 4$

S31 A001 $=\mathrm{k} 1 / \mathrm{k} 3 / \mathrm{k} 5 ; \quad$ A010 $=\mathrm{k} 1 / \mathrm{k} 4 / \mathrm{k} 6 / \mathrm{k} 8$; $\mathrm{A} 005=\mathrm{k} 1 / \mathrm{k} 6 ; \quad \mathrm{A} 006=\mathrm{k} 4 ; \quad$ A008 $=\mathrm{k} 4$; $\mathrm{A} 007=\mathrm{k} 4$

S32 A001=k1/k3/k5; A010=k1/k4/k6/k8; $\mathrm{A} 005=\mathrm{k} 1 / \mathrm{k} 6 ; \mathrm{A} 006=\mathrm{k} 4 ; \mathrm{A} 008=\mathrm{k} 4$

S33 A001 $=\mathrm{k} 1 / \mathrm{k} 3 / \mathrm{k} 5 ; \quad \mathrm{A} 010=\mathrm{k} 1 / \mathrm{k} 4 / \mathrm{k} 6 / \mathrm{k} 8$; $\mathrm{A} 005=\mathrm{k} 1 / \mathrm{k} 6 ; \mathrm{A} 006=\mathrm{k} 4 ; \mathrm{A} 007=\mathrm{k} 4$

$\mathrm{S} 34 \quad \mathrm{~A} 001=\mathrm{k} 1 / \mathrm{k} 3 / \mathrm{k} 5 ; \quad \mathrm{A} 010=\mathrm{k} 1 / \mathrm{k} 4 / \mathrm{k} 6 / \mathrm{k} 8$; $\mathrm{A} 005=\mathrm{k} 1 / \mathrm{k} 6 ; \mathrm{A} 006=\mathrm{k} 4$

$\mathrm{S} 35 \quad \mathrm{~A} 001=\mathrm{k} 1 / \mathrm{k} 3 / \mathrm{k} 5 ; \quad \mathrm{A} 010=\mathrm{k} 1 / \mathrm{k} 4 / \mathrm{k} 6 / \mathrm{k} 8 ;$ $\mathrm{A} 005=\mathrm{k} 1 / \mathrm{k} 6 ; \mathrm{A} 003=\mathrm{k} 4$

S36 A001 $=\mathrm{k} 1 / \mathrm{k} 3 / \mathrm{k} 5 ; \quad \mathrm{A} 010=\mathrm{k} 1 / \mathrm{k} 4 / \mathrm{k} 6 / \mathrm{k} 8$; $\mathrm{A} 005=\mathrm{k} 1 / \mathrm{k} 6 ; \mathrm{A} 008=\mathrm{k} 4 ; \mathrm{A} 007=\mathrm{k} 4$

S37 A001 $=\mathrm{k} 1 / \mathrm{k} 3 / \mathrm{k} 5 ; \quad \mathrm{A} 010=\mathrm{k} 1 / \mathrm{k} 4 / \mathrm{k} 6 / \mathrm{k} 8$; $\mathrm{A} 005=\mathrm{k} 1 / \mathrm{k} 6 ; \mathrm{A} 008=\mathrm{k} 4$

S38 A001=k1/k3/k5; A010=k1/k4/k6/k8; $\mathrm{A} 005=\mathrm{k} 1 / \mathrm{k} 6 ; \mathrm{A} 007=\mathrm{k} 4$

S39 A001 $=\mathrm{k} 1 / \mathrm{k} 3 / \mathrm{k} 5 ; \quad \mathrm{A} 010=\mathrm{k} 1 / \mathrm{k} 4 / \mathrm{k} 6 / \mathrm{k} 8$; $\mathrm{A} 005=\mathrm{k} 1 / \mathrm{k} 6$

$\mathrm{S} 40 \quad \mathrm{~A} 001=\mathrm{k} 1 / \mathrm{k} 3 / \mathrm{k} 5 ; \quad \mathrm{A} 003=\mathrm{k} 4 ; \quad \mathrm{A} 005=\mathrm{k} 1 / \mathrm{k} 6 ;$ $\mathrm{A} 010=\mathrm{k} 1 / \mathrm{k} 4 / \mathrm{k} 6 / \mathrm{k} 8 ; \mathrm{A} 011=\mathrm{k} 7 ; \mathrm{A} 012=\mathrm{k} 7$

S41 A001 $=\mathrm{k} 1 / \mathrm{k} 3 / \mathrm{k} 5 ; \quad \mathrm{A} 003=\mathrm{k} 4 ; \quad \mathrm{A} 005=\mathrm{k} 1 / \mathrm{k} 6$; $\mathrm{A} 010=\mathrm{k} 1 / \mathrm{k} 4 / \mathrm{k} 6 / \mathrm{k} 8 ; \mathrm{A} 012=\mathrm{k} 7$

$\mathrm{S} 42 \quad \mathrm{~A} 001=\mathrm{k} 1 / \mathrm{k} 3 / \mathrm{k} 5 ; \mathrm{A} 003=\mathrm{k} 4 ; \mathrm{A} 005=\mathrm{k} 1 / \mathrm{k} 6$; $\mathrm{A} 010=\mathrm{k} 1 / \mathrm{k} 4 / \mathrm{k} 6 / \mathrm{k} 8 ; \mathrm{A} 013=\mathrm{k} 7 ; \mathrm{A} 014=\mathrm{k} 7$

$\mathrm{S} 43 \quad \mathrm{~A} 001=\mathrm{k} 1 / \mathrm{k} 3 / \mathrm{k} 5 ; \mathrm{A} 003=\mathrm{k} 4 ; \mathrm{A} 005=\mathrm{k} 1 / \mathrm{k} 6$; $\mathrm{A} 010=\mathrm{k} 1 / \mathrm{k} 4 / \mathrm{k} 6 / \mathrm{k} 8 ; \mathrm{A} 014=\mathrm{k} 7$

$\mathrm{S} 44 \quad \mathrm{~A} 001=\mathrm{k} 1 / \mathrm{k} 3 / \mathrm{k} 5 ; \quad \mathrm{A} 003=\mathrm{k} 4 ; \quad \mathrm{A} 005=\mathrm{k} 1 / \mathrm{k} 6 ;$ $\mathrm{A} 010=\mathrm{k} 1 / \mathrm{k} 4 / \mathrm{k} 6 / \mathrm{k} 8 ; \mathrm{A} 016=\mathrm{k} 7$

S45 A001 $=\mathrm{k} 1 / \mathrm{k} 3 / \mathrm{k} 5 ; \quad \mathrm{A} 003=\mathrm{k} 4 ; \quad \mathrm{A} 005=\mathrm{k} 1 / \mathrm{k} 6 ;$ $\mathrm{A} 010=\mathrm{k} 1 / \mathrm{k} 4 / \mathrm{k} 6 / \mathrm{k} 8 ; \mathrm{A} 017=\mathrm{k} 7$

$\mathrm{S} 46 \quad \mathrm{~A} 001=\mathrm{k} 1 / \mathrm{k} 3 / \mathrm{k} 5 ; \mathrm{A} 003=\mathrm{k} 4 ; \mathrm{A} 005=\mathrm{k} 1 / \mathrm{k} 6 ;$

\section{KODE SOLUSI}

$\mathrm{A} 010=\mathrm{k} 1 / \mathrm{k} 4 / \mathrm{k} 6 / \mathrm{k} 8 ; \mathrm{A} 018=\mathrm{k} 7$

$\mathrm{A} 001=\mathrm{k} 1 / \mathrm{k} 3 / \mathrm{k} 5 ; \quad \mathrm{A} 003=\mathrm{k} 4 ; \quad \mathrm{A} 005=\mathrm{k} 1 / \mathrm{k} 6$; $\mathrm{A} 010=\mathrm{k} 1 / \mathrm{k} 4 / \mathrm{k} 6 / \mathrm{k} 8 ; \mathrm{A} 019=\mathrm{k} 7$

S48 A001=k1/k3/k5; A003=k4; A005=k1/k6; $\mathrm{A} 010=\mathrm{k} 1 / \mathrm{k} 4 / \mathrm{k} 6 / \mathrm{k} 8 ; \mathrm{A} 020=\mathrm{k} 7$

S49 A001 $=\mathrm{k} 1 / \mathrm{k} 3 / \mathrm{k} 5 ; \quad \mathrm{A} 003=\mathrm{k} 4 ; \quad \mathrm{A} 005=\mathrm{k} 1 / \mathrm{k} 6$; $\mathrm{A} 010=\mathrm{k} 1 / \mathrm{k} 4 / \mathrm{k} 6 / \mathrm{k} 8 ; \mathrm{A} 021=\mathrm{k} 7$

S50 A001 $=\mathrm{k} 1 / \mathrm{k} 3 / \mathrm{k} 5 ; \quad \mathrm{A} 003=\mathrm{k} 2 / \mathrm{k} 4$ $\mathrm{A} 005=\mathrm{k} 1 / \mathrm{k} 6 ; \mathrm{A} 010=\mathrm{k} 1 / \mathrm{k} 4 / \mathrm{k} 6 / \mathrm{k} 8$

S51 A001=k1/k3/k5; A003=k2/k4; $\mathrm{A} 015=\mathrm{k} 2 / \mathrm{k} 4 ; \mathrm{A} 012=\mathrm{k} 7 ; \mathrm{A} 011=\mathrm{k} 7$

$\mathrm{S} 52 \mathrm{~A} 001=\mathrm{k} 1 / \mathrm{k} 3 / \mathrm{k} 5 ; \quad \mathrm{A} 003=\mathrm{k} 2 / \mathrm{k} 4 ;$ $\mathrm{A} 015=\mathrm{k} 2 / \mathrm{k} 4 ; \quad \mathrm{A} 012=\mathrm{k} 1 / \mathrm{k} 6 ; \quad$ A013=k7; $\mathrm{A} 014=\mathrm{k} 7$

S53 A001=k1/k3/k5; A003=k2/k4; $\mathrm{A} 015=\mathrm{k} 2 / \mathrm{k} 4 ; \quad$ A012 $=\mathrm{k} 1 / \mathrm{k} 6$

$\mathrm{A} 014=\mathrm{k} 1 / \mathrm{k} 4 / \mathrm{k} 6 ; \mathrm{A} 016=\mathrm{k} 7$

S54 A001=k1/k3/k5; A003=k2/k4; $\mathrm{A} 015=\mathrm{k} 2 / \mathrm{k} 4 ; \quad \mathrm{A} 012=\mathrm{k} 1 / \mathrm{k} 6$

$\mathrm{A} 014=\mathrm{k} 1 / \mathrm{k} 4 / \mathrm{k} 6 ; \mathrm{A} 017=\mathrm{k} 7$

S55 A001 $=\mathrm{k} 1 / \mathrm{k} 3 / \mathrm{k} 5 ; \quad$ A003 $=\mathrm{k} 2 / \mathrm{k} 4$

$\mathrm{A} 015=\mathrm{k} 2 / \mathrm{k} 4 ; \quad$ A012=k1/k6;

$\begin{array}{ll}\mathrm{A} 014=\mathrm{k} 1 / \mathrm{k} 4 / \mathrm{k} 6 ; \mathrm{A} 018=\mathrm{k} 7 & \\ \mathrm{~A} 001=\mathrm{k} 1 / \mathrm{k} 3 / \mathrm{k} 5 ; & \mathrm{A} 003=\mathrm{k} 2 / \mathrm{k} 4\end{array}$

S56 A001=k1/k3/k5; A003=k2/k4;

$\mathrm{A} 015=\mathrm{k} 2 / \mathrm{k} 4 ; \quad \mathrm{A} 012=\mathrm{k} 1 / \mathrm{k} 6$

$\mathrm{A} 014=\mathrm{k} 1 / \mathrm{k} 4 / \mathrm{k} 6 ; \mathrm{A} 019=\mathrm{k} 7 \quad \mathrm{~A} 003=\mathrm{k} 2 / \mathrm{k} 4 ;$
$\mathrm{A} 001=\mathrm{k} 1 / \mathrm{k} 3 / \mathrm{k} 5 ;$

S57 A001=k1/k3/k5; $\quad$ A003 $=\mathrm{k} 2 / \mathrm{k} 4 ;$

$\mathrm{A} 014=\mathrm{k} 1 / \mathrm{k} 4 / \mathrm{k} 6 ; \mathrm{A} 020=\mathrm{k} 7$

S58 A001=k1/k3/k5; $\quad$ A003 $=\mathrm{k} 2 / \mathrm{k} 4$;

$\mathrm{A} 015=\mathrm{k} 2 / \mathrm{k} 4 ; \quad \mathrm{A} 012=\mathrm{k} 1 / \mathrm{k} 6$;

$\mathrm{A} 014=\mathrm{k} 1 / \mathrm{k} 4 / \mathrm{k} 6 ; \mathrm{A} 021=\mathrm{k} 7 \quad \mathrm{~A} 003=\mathrm{k} 2 / \mathrm{k} 4 ;$
$\mathrm{A} 001=\mathrm{k} 1 / \mathrm{k} 3 / \mathrm{k} 5 ;$

A015=k2/k4; A012=k1/k6;

$\mathrm{A} 014=\mathrm{k} 1 / \mathrm{k} 4 / \mathrm{k} 6$

$\mathrm{S} 60 \quad \mathrm{~A} 001=\mathrm{k} 1 / \mathrm{k} 3 / \mathrm{k} 5 ; \quad \mathrm{A} 008=\mathrm{k} 4 ; \quad \mathrm{A} 007=\mathrm{k} 4 ;$ $\mathrm{A} 005=\mathrm{k} 1 / \mathrm{k} 6 ; \quad \mathrm{A} 010=\mathrm{k} 1 / \mathrm{k} 4 / \mathrm{k} 6 / \mathrm{k} 8$;

$\mathrm{A} 011=\mathrm{k} 7 ; \mathrm{A} 012=\mathrm{k} 7$

S61 A001 $=\mathrm{k} 1 / \mathrm{k} 3 / \mathrm{k} 5 ; \quad \mathrm{A} 008=\mathrm{k} 4 ; \quad \mathrm{A} 007=$ $\mathrm{A} 005=\mathrm{k} 1 / \mathrm{k} 6 ; \quad \mathrm{A} 010=\mathrm{k} 1 / \mathrm{k} 4 / \mathrm{k} 6 / \mathrm{k} 8$; $\mathrm{A} 012=\mathrm{k} 7$

$\mathrm{S} 62 \quad \mathrm{~A} 001=\mathrm{k} 1 / \mathrm{k} 3 / \mathrm{k} 5 ; \quad \mathrm{A} 008=\mathrm{k} 4 ; \quad \mathrm{A} 007=$ $\mathrm{A} 005=\mathrm{k} 1 / \mathrm{k} 6 ; \quad \mathrm{A} 010=\mathrm{k} 1 / \mathrm{k} 4 / \mathrm{k} 6 / \mathrm{k} 8$;

$\mathrm{A} 013=\mathrm{k} 7 ; \mathrm{A} 014=\mathrm{k} 7$

$\mathrm{S} 63 \quad \mathrm{~A} 001=\mathrm{k} 1 / \mathrm{k} 3 / \mathrm{k} 5 ; \quad \mathrm{A} 008=\mathrm{k} 4 ; \quad \mathrm{A} 007=$ $\mathrm{A} 005=\mathrm{k} 1 / \mathrm{k} 6 ; \quad \mathrm{A} 010=\mathrm{k} 1 / \mathrm{k} 4 / \mathrm{k} 6 / \mathrm{k} 8$;

$\mathrm{A} 014=\mathrm{k} 7$

$\mathrm{S} 64 \quad \mathrm{~A} 001=\mathrm{k} 1 / \mathrm{k} 3 / \mathrm{k} 5 ; \quad \mathrm{A} 008=\mathrm{k} 4 ; \quad \mathrm{A} 007=$ $\mathrm{A} 005=\mathrm{k} 1 / \mathrm{k} 6 ; \quad \mathrm{A} 010=\mathrm{k} 1 / \mathrm{k} 4 / \mathrm{k} 6 / \mathrm{k} 8$;

$\mathrm{A} 016=\mathrm{k} 7$

S65 A001 $=\mathrm{k} 1 / \mathrm{k} 3 / \mathrm{k} 5 ; \quad \mathrm{A} 008=\mathrm{k} 4 ; \quad \mathrm{A} 007=$ $\mathrm{A} 005=\mathrm{k} 1 / \mathrm{k} 6 ; \quad \mathrm{A} 010=\mathrm{k} 1 / \mathrm{k} 4 / \mathrm{k} 6 / \mathrm{k} 8$;

$\mathrm{A} 017=\mathrm{k} 7$

S66 A001=k1/k3/k5; A008=k4; A007= $\mathrm{A} 005=\mathrm{k} 1 / \mathrm{k} 6 ; \quad \mathrm{A} 010=\mathrm{k} 1 / \mathrm{k} 4 / \mathrm{k} 6 / \mathrm{k} 8$;

$\mathrm{A} 018=\mathrm{k} 7$

S67 A001=k1/k3/k5; A008=k4; A007= $\mathrm{A} 005=\mathrm{k} 1 / \mathrm{k} 6 ; \quad \mathrm{A} 010=\mathrm{k} 1 / \mathrm{k} 4 / \mathrm{k} 6 / \mathrm{k} 8$;

$\mathrm{A} 019=\mathrm{k} 7$

S68 A001 $=\mathrm{k} 1 / \mathrm{k} 3 / \mathrm{k} 5 ; \quad \mathrm{A} 008=\mathrm{k} 4 ; \quad \mathrm{A} 007=$ $\mathrm{A} 005=\mathrm{k} 1 / \mathrm{k} 6 ; \quad \mathrm{A} 010=\mathrm{k} 1 / \mathrm{k} 4 / \mathrm{k} 6 / \mathrm{k} 8$; $\mathrm{A} 020=\mathrm{k} 7$ 


\begin{tabular}{|c|c|}
\hline KODE & SOLUSI \\
\hline S69 & $\begin{array}{lrr}\text { A001 }=\mathrm{k} 1 / \mathrm{k} 3 / \mathrm{k} 5 ; & \mathrm{A} 008=\mathrm{k} 4 ; \quad \mathrm{A} 007= \\
\mathrm{A} 005=\mathrm{k} 1 / \mathrm{k} 6 ; & \mathrm{A} 010=\mathrm{k} 1 / \mathrm{k} 4 / \mathrm{k} 6 / \mathrm{k} 8 ; \\
\text { A021 }=\mathrm{k} 7 & \end{array}$ \\
\hline S70 & $\begin{array}{l}\mathrm{A} 001=\mathrm{k} 1 / \mathrm{k} 3 / \mathrm{k} 5 ; \quad \mathrm{A} 008=\mathrm{k} 4 ; \\
\mathrm{A} 005=\mathrm{k} 1 / \mathrm{k} 6 ; \mathrm{A} 010=\mathrm{k} 1 / \mathrm{k} 4 / \mathrm{k} 6 / \mathrm{k} 8\end{array}$ \\
\hline S71 & $\begin{array}{l}\mathrm{A} 001=\mathrm{k} 1 / \mathrm{k} 3 / \mathrm{k} 5 ; \quad \mathrm{A} 008=\mathrm{k} 4 ; \quad \text { A007=k4; } \\
\mathrm{A} 015=\mathrm{k} 2 / \mathrm{k} 4 ; \mathrm{A} 012=\mathrm{k} 7 ; \mathrm{A} 011=\mathrm{k} 7\end{array}$ \\
\hline S72 & 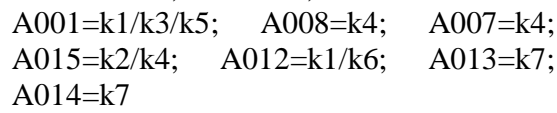 \\
\hline S73 & $\begin{array}{l}\mathrm{A} 001=\mathrm{k} 1 / \mathrm{k} 3 / \mathrm{k} 5 ; \quad \mathrm{A} 008=\mathrm{k} 4 ; \quad \begin{array}{r}\mathrm{A} 007=\mathrm{k} 4 ; \\
\mathrm{A} 015=\mathrm{k} 2 / \mathrm{k} 4 ;\end{array} \\
\mathrm{A} 014=\mathrm{k} 1 / \mathrm{k} 4 / \mathrm{k} 6 ;\end{array}$ \\
\hline S74 & $\begin{array}{l}\mathrm{A} 001=\mathrm{k} 1 / \mathrm{k} 3 / \mathrm{k} 5 ; \quad \mathrm{A} 008=\mathrm{k} 4 ; \quad \mathrm{A} 007=\mathrm{k} 4 ; \\
\mathrm{A} 015=\mathrm{k} 2 / \mathrm{k} 4 ; \\
\mathrm{A} 014=\mathrm{k} 1 / \mathrm{k} 4 / \mathrm{k} 6 ;\end{array}$ \\
\hline S75 & $\begin{array}{l}\mathrm{A} 001=\mathrm{k} 1 / \mathrm{k} 3 / \mathrm{k} 5 ; \quad \mathrm{A} 008=\mathrm{k} 4 ; \quad \begin{array}{r}\mathrm{A} 007=\mathrm{k} 4 ; \\
\mathrm{A} 015=\mathrm{k} 2 / \mathrm{k} 4 ; \\
\mathrm{A} 014=\mathrm{k} 1 / \mathrm{k} 4 / \mathrm{k} 6 ;\end{array} \text { A018=k7 }\end{array}$ \\
\hline S76 & $\begin{array}{l}\text { A001 }=\mathrm{k} 1 / \mathrm{k} 3 / \mathrm{k} 5 ; \quad \text { A008=k4; } \quad \begin{array}{l}\mathrm{A} 007=\mathrm{k} 4 ; \\
\mathrm{A} 015=\mathrm{k} 2 / \mathrm{k} 4 ;\end{array} \\
\text { A014=k1/k4/k6; }\end{array}$ \\
\hline S77 & $\begin{array}{l}\mathrm{A} 001=\mathrm{k} 1 / \mathrm{k} 3 / \mathrm{k} 5 ; \text { A } \mathrm{A} 008=\mathrm{k} 4 ; \mathrm{A} 007=\mathrm{k} 4 \\
\mathrm{~A} 003=\mathrm{k} 2 / \mathrm{k} 4 ; \text { A015=k2/k4; A012=k1/k6; } \\
\text { A014=k1/k4/k6; A020=k7 }\end{array}$ \\
\hline S78 & 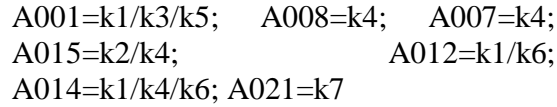 \\
\hline S79 & 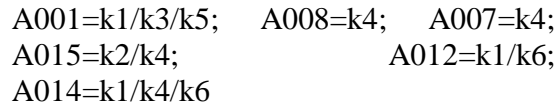 \\
\hline
\end{tabular}

\section{Usecase Diagram}

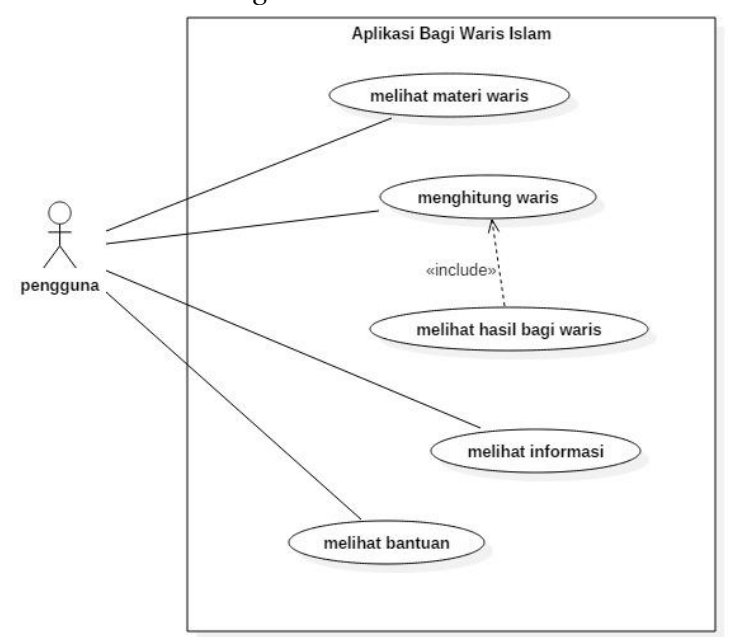

Gambar 3. Usecase Diagram Aplikasi Bagi Waris Islam

Dibawah ini merupakan implementasi dari program yang dibuat:

A. Halaman Awal

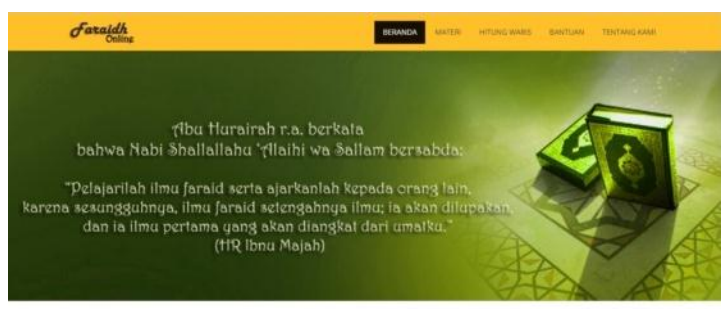

BAGI WARIS ISLAM
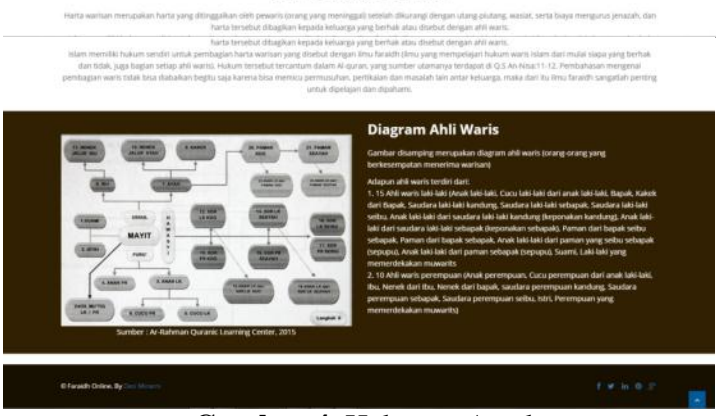

Gambar 4. Halaman Awal

B. Halaman Materi

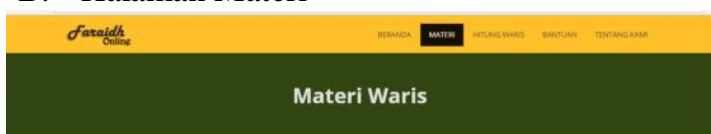

Dasar Illmu Waris

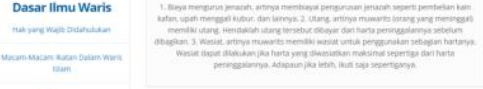

nam

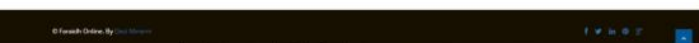

Gambar 5. Halaman Materi

C. Halaman Hitung Waris
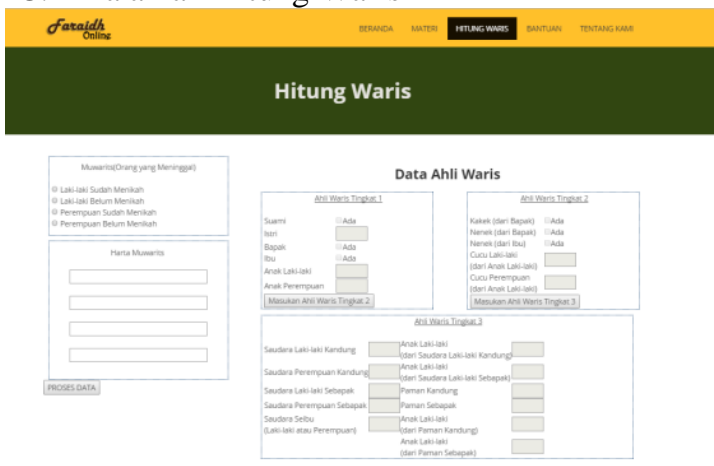

Gambar 6. Halaman Hitung Waris 


\section{Hasil Perhitungan}

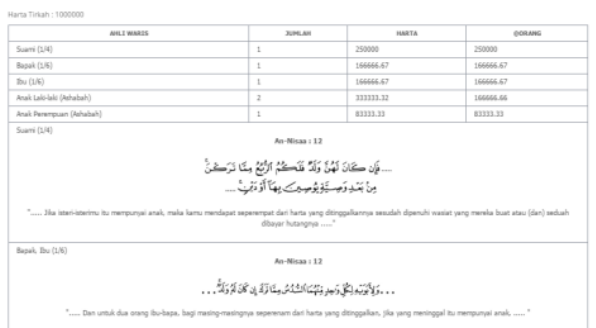

Gambar 7. Halaman Hasil Perhitungan

\section{PENUTUP}

Hasil dari penelitian ini dapat disimpulkan bahwa:

1. Dengan dibangunnya aplikasi dapat mempermudah dan mempercepat proses perhitungan bagi waris Islam. Pengguna hanya memasukan data ahli waris, muwarits, dan harta warisan tanpa harus menghitung satu persatu bagian harta setiap ahli waris.

2. Aplikasi dapat meminimalisir kesalahan dan menambah keakuratan dalam hasil perhitungan, karena dalam aplikasi sudah tertanam rumus-rumus perhitungan yang akan memproses data yang dimasukan pengguna.

3. Selain untuk melakukan proses perhitungan bagi waris, aplikasi dapat digunakan sebagai media pembelajaran. Dengan adanya rujukan ayat dari hasil perhitungan, pengguna dapat mengetahui ayat-ayat yang mendasari diambilnya keputusan tersebut. Sehingga dapat membantu masyarakat yang ingin mempelajari ilmu faraidh dan kembali menjalankan aturan yang terdapat dalam alquran.

\section{REFERENSI}

[1] Kusrini. (2008). "Aplikasi Sistem Pakar". Yogyakarta: ANDI.

[2] Pasha, Musthafa Kamal., dkk. (2009). "FIKIH ISLAM". Yogyakarta: Citra Karsa Mandiri.

[3] Setiawan, Ridwan., Dini Destiani, Cepy Slamet. "Perancangan Sistem Pakar untuk Pembagian Waris Menurut Hukum Islam (Fara'id)". (2012). Jurnal Algoritma ISSN:2302-7339 Vol.09 No.01 STT Garut.

[4] Tutik A, Gusti Ayu Kadek. Dkk. "Penerapan Forward Chaining Pada Program Diagnosa Anak Penderita Autisme". (2009). Jurnal Informatika, Vol 5 No 2. 